СВ. П. ПОЛЬОВИЙ, БІЛЕЛ КХОРШАНІ, О. В. РОТАР, О. М. ПЛЕГУЦА, П. М. ВОЛЯНЮК, О. Й. ХОМКО, П. В. КИФЯК, І. М. ПЛЕГУЦА, Р. І. СИДОРЧУК

ВДнЗ України “Буковинський державний медичний університет”, Чернівці

\title{
Індивідуалізована хірургічна тактика при синдромі діабетичної стопи
}

\begin{abstract}
Мета роботи: розробити індивідуалізований алгоритм хірургічного лікування хворих на синдром діабетичної стопи (СДС). Матеріали і методи. Комплексне клінічне дослідження охоплює 123 випадки хірургічного лікування СДС (хворі різних ступенів за класифікацією PEDIS, I-V стадій за F. Wagner, з легкою, помірною, тяжкою інфекцією за IDSA). Розробку алгоритму хірургічної активності при СДС здійснювали згідно з рекомендаціями Institute for Algorithmic Medicine (Г’юстон, США), з використанням програмного (HTML/XML/GMT) пакету Document Exploration and Linking Tool / Addons (DELTA), розробленого Vienna University of Technology, Institute of Software Technology and Interactive Systems, Information Engineering Group, Vienna, Austria.

Результати досліджень та їх обговорення. Ангіографічний або технічний успіх ендоваскулярних втручань, що призводить до істотного збільшення просвіту судини в зоні стенозу або оклюзії, ми отримали в 94,3 \% спостережень. Технічний успіх балонної ангіопластики спостерігали практично в усіх випадках, дещо гірші ангіографічні результати отримано при втручаннях на декількох артеріях гомілки - 55,0-94,1 \% успішних ангіопластик. При ішемічній та змішаній нейроішемічній формах у більшості хворих вдавалося компенсувати критичну ішемію виконанням судинних втручань. Запропонований алгоритм хірургічних втручань при СДС потребує подальшого вивчення за умов більшої рандомізації та розширення когорти пацієнтів.
\end{abstract}

Ключові слова: синдром стопи діабетика; лікування; хірургія; алгоритм.

Постановка проблеми і аналіз останніх досліджень та публікацій. Цукровий діабет (ЦД) є одним з найбільш поширених хронічних захворювань сучасності. Понад 70 \% хворих на ЦД страждають на різноманітні ускладнення діабету, серед яких найбільш поширеним є синдром стопи діабетика, або синдром діабетичної стопи (СДС), що є складним симптомокомплексом морфофункціональних та патогенетичних змін у тканинах нижніх кінцівок на фоні діабетичної мікро-, макроангіопатії, невропатії, остеоартропатії. У більшості хворих на СДС реєструють гнійно-некротичні процеси (ГНП) стопи та гомілки, що майже у половині випадків закінчується вимушеними ампутаціями [1].

Частота таких ампутацій у хворих на СДС, за даними різних досліджень, посідає перше місце серед усіх ампутацій нетравматичного характеру та у десятки разів вище, ніж в осіб, які не страждають на ЦД. Майже 30 \% пацієнтів після первинної ампутації піддаються ампутації іншої кінцівки впродовж найближчих 3-5 років та майже половина у наступні роки. Високі рівні інвалідизації та летальності зумовлюють медичну та соціальноекономічну значимість захворювання [2].

Відповідно до існуючих рекомендацій, загальні принципи лікування хворих на СДС [1, 3] включають компенсацію та нормалізацію метаболізму, у тому числі вуглеводного, корекцію органної дисфункції, детоксикацію; раціональну системну етіотропну антибактеріальну терапію; ліквіда- цію/корекцію ангіо- та нейропатії, розвантаження (іммобілізацію) кінцівки; зменшення набряку та ішемії; своєчасне необхідне й адекватне хірургічне втручання; локальне лікування хронічної рани (виразки або інших дефектів покривних та м'яких тканин). Існують суттєві розбіжності у трактуванні багатьох аспектів лікування хворих на СДС, особливо це стосується вибору, етапності хірургічних втручань. На сучасному етапі сформовані протилежні погляди на хірургічну активність при СДС. 3 одного боку - виконання радикальних втручань вже на початку розвитку гнійно-некротичних процесів, що обгрунтовується неминучістю подальших патологічних змін, з іншого - максимальна обмеженість втручань, що обгрунтовується високим ризиком виникнення їх ускладнень [4-6]. Як наслідок, виникає високий ризик необгрунтованого вибору методів та етапності хірургічного лікування у хворих на СДС [7].

Вищенаведене визначає необхідність розробки індивідуалізованого підходу щодо хірургічного лікування хворих на синдром діабетичної стопи.

Мета роботи: розробити індивідуалізований алгоритм хірургічного лікування хворих на синдром діабетичної стопи.

Матеріали і методи. Проведено комплексне клінічне дослідження 123 випадки хірургічного лікування СДС (хворі різних ступенів за класифікацією PEDIS, I-V стадій за F. Wagner, з легкою, помірною, 
тяжкою інфекцією за IDSA), на базі клініки загальної хірургії [2, 8]. При виконанні дослідження керувались загальноприйнятими нормами біоетики відповідно до Директиви ЄЕС № 609 від 24.11.1986 р., GCP (1996 р.), Конвенції Ради Європи про права людини та біомедицину (від 04.04.1997р.), Гельсінської декларації Всесвітньої медичної асоціації про етичні принципи проведення наукових медичних досліджень за участю людини (1964-2000рр.), наказу МОЗ України № 281 від 01.11.2000 р. та наказу МО3 України № 616 від 03.08.2012 р. У контингенті хворих переважали особи чоловічої статі, також чоловіки були молодші, ніж жінки - $(59,26 \pm 14,48)$ р. проти $(65,76 \pm 7,60)$ р., однак ця різниця була недостатньо вірогідною ( $\mathrm{P}=0,72)$.

У дослідження включали як хворих на ішемічну та змішану форми СДС $(69,1 \%)$, так і хворих із нейропатичною формою СДС (30,9 \%). Рановий процес у пацієнтів включав інфіковані (гнійні) рани - 42 (35,0 \%) хворих, трофічні виразки 39 (32,5 \%) хворих та гангрена пальців стоп - 39 (32,5 \%) хворих; також було 3 (2,5 \%) хворих з іншими формами локального враження при СДС. Як контроль використано дані літературних джерел та попередніх власних досліджень [5-7, 9]. Для виявлення клінічних особливостей перебігу захворювання, встановлення діагнозу та визначення ефективності застосованих хірургічних підходів використовували загальноклінічні, лабораторні, біохімічні, інструментальні, УЗД (визначення плечо-гомілкового індексу в динаміці) рентгенографічні (комп’ютерна ангіографія), електрокардіографічні методи дослідження тощо. При виконанні операційних втручань (визначенні показів та протипоказань) користувались рекомендаціями джерел літератури. Статистичну обробку, спрямовану на розробку алгоритму хірургічної активності при СДС, здійснювали згідно з рекомендаціями Institute for Algorithmic Medicine (Г’юстон, США), з використанням програмного (HTML/XML/GMT) пакету Document Exploration and Linking Tool / Addons (DELTA) розробленого Vienna University of Technology, Institute of Software Technology and Interactive Systems, Information Engineering Group, Vienna, Austria [10, 11].

Результати досліджень та їх обговорення. Ангіографічний або технічний успіх ендоваскулярних втручань, що призводить до істотного збільшення просвіту судини в зоні стенозу або оклюзії, ми отримали в 94,3 \% спостережень. Технічний успіх балонної ангіопластики спостерігався практично в усіх випадках, гірші ангіографічні результати отримано при втручаннях на декількох артеріях гомілки - 55,0-94,1\% успішних ангіопластик. У хворих на СДС нейропатичної форми, при технічних труднощах, а також при збереженні нормальної прохідності артеріальних судин за даними УЗД, плечо-гомілкового індексу та ангіографії у хворих змішаної та ішемічної форми - вважали проведення ендоваскулярних операційних втручань неможливим.

У таких хворих застосовували методи непрямої реваскуляризації згідно 3 алгоритмом (рис.). За умов СДС 0-1 ст. (за F. Wagner) ізольованої нейропатичної форми, виконання операційних втручань було недоцільне, що узгоджується з рекомендаціями. Наявність виражених остеоартропатій (СДС 2 ст.) спонукала виконувати етапні некректомії, реконструктивні втручання на стопі та різні види пластики дефектів. Початкова гангрена, кістково-деструктивні процеси, стопа Charcot (СДС 3-4 ст.) - потребували комплексного етапного хірургічного підходу, який включав некректомії $з$ резекцією та екзартикуляцією уражених сегментів та ампутації з наступними реконструктивно-пластичними втручаннями (авто- та алопластика, колагенові біопокриття, сітчасті імпрегновані покриття, гіалуронові ін'єкції, комбіновані пластичні вакуум-асистовані пов'язки, клітинні та тканинні препарати тощо). Ампутацію кінцівок виконувалт тільки при високих гангренах.

При ішемічній та змішаній нейроішемічній формах у більшості хворих вдавалося компенсувати критичну ішемію виконанням судинних втручань. Найбільш поширена причина невдалого ангіографічного результату таких втручань була технічна неможливість проходження зони оклюзійного ураження при спробах її реканалізації (2 випадків), в одному випадку не вдалося провести провідник за зону стенозу. Хоча нам не вдалося відновити кровообіг, у цих пацієнтів клінічний стан кінцівок, що піддалися втручанню, в цілому не погіршився, оскільки компенсація була досягнута за рахунок одночасної ангіопластики інших артерій гомілки. Об'єктивований рівень компенсації критичної ішемії контролювали в динаміці за допомогою плечо-гомілкового індексу (brachialankle index), при цьому, згідно з рекомендаціями $[1,8]$, пороговими значеннями вважали показники 0,7 та 0,5. Отримані показники застосовували для корекції оперативної тактики, при цьому визначали ії згідно з алгоритмом, який застосовували у хворих, які не підлягали судинним втручанням.

Пропонований алгоритм хірургічної тактики при синдромі стопи діабетика загалом узгоджується 3 сучасними рекомендаціями 3 лікування хворих на СДС $[2,10]$, вносячи певні уточнення та 


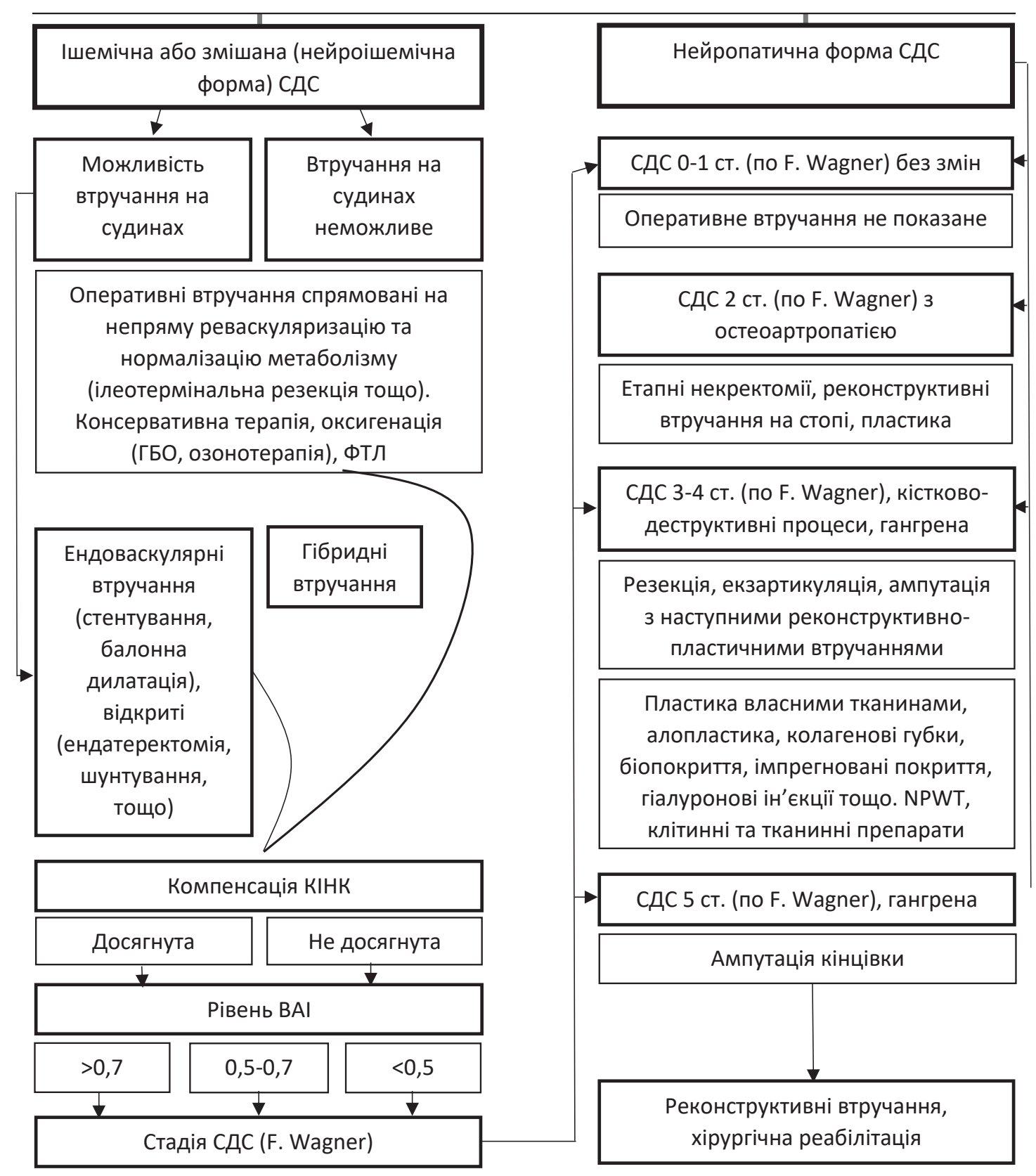

Рис. Алгоритм застосування методів непрямої реваскуляризації.

модифікації. Наприклад, ми вважаємо доцільним застосовувати ендоваскулярні операційні втручання у всіх хворих на ішемічну та змішану форми СДС, в яких виконання таких втручань можливе. Обмежити показання до судинних втручань можна за рахунок технічних труднощів та наявності ознак синдрому системної запальної відповіді, що суттєво підвищує ризики ускладнень.

Дане дослідження має певні обмеження, зумовлені розміром вибірки, недостатньою контрольованістю та рандомізацією контингенту пацієнтів. Також важливим обмеженням роботи є ізо- льований розгляд тільки хірургічного підходу до лікування СДС, без урахування консервативної терапії та локального лікування таких хворих.

Висновки. 1. Показання до виконання БАП можуть бути розширені при багаторівневих СОУ артерій у хворих 3 ішемічною формою СДС та KIHК у випадках неможливості виконання відкритої реконструкції через тяжку супутню патологію, відсутності пластичного матеріалу або поширених трофічних змінах ураженої кінцівки. 2. Запропонований алгоритм хірургічних втручань при СДС по- 
требує подальшого вивчення за умов більшої рандомізації та розширення когорти пацієнтів.

Перспективи подальших досліджень. Незважаючи на те, що існує багато методів хірургіч- них втручань при СДС, їх результативність не завжди задовільна. Лікування рубців СДС - тривалий та складно прогнозований щодо кінцевого результату процес, який є актуальною клінічною проблемою і потребує подальшого вирішення.

\section{СПИСОК ЛІТЕРАТУРИ}

1. On behalf of the International Working Group on the Diabetic Foot (IWGDF). IWGDF Guidelines on the Prevention and Management of Diabetic Foot Disease / N. C. Schaper, J. van Netten, J. Apelqvist [et al.]. - Access mode : 16.04.2020 from https://iwgdfguidelines.org/wp-content/uploads/2019/05/01IWGDF-practical-guidelines-2019.pdf.

2. CODIFI (Concordance in Diabetic Foot Ulcer Infection): a cross-sectional study of wound swab versus tissue sampling in infected diabetic foot ulcers in England / A. Nelson, A. WrightHughes, M. R. Backhouse [et al.] // BMJ Open. - 2018. - Vol. 8 (1). - e019437.

3. Chen S. Y. Invasive systemic infection after hospital treatment for diabetic foot ulcer: Risk of occurrence and effect on survival / S. Y. Chen, J. M. Giurini, A. W. Karchmer // Clin. Infect. Dis. 2017. - Vol. 64 (3). - P. 326-334.

4. Sartelli M. Physiological parameters for prognosis in abdominal sepsis (PIPAS) study: a WSES observational study / M. Sartelli, Abu-Zidan, F.M. Labricciosa, [et al.] // World J. Emerg. Surg. 2019. - Vol. 14 (34). Access mode : https://doi. org/10.1186/s13017-019-0253-2.

5. Status of immunity cellular link in diabetic foot syndrome / O. Y. Khomko, R. I. Sydorchuk, P. M. Volyanyuk [et al.] // Klin. khirurgiia. - 2017. - No. 8. - P. 48-49.

6. Павлович К. В. Використання ін'єкційного матеріалу для

регенерації шкіри лацерта® для лікування трофічних виразок у хворих при синдромі діабетичної стопи / К. В. Павлович, Р. І. Сидорчук // Клін. хірургія. - 2015. - № 7. - С. 44-46. 7. Microbiota alleviates host resistance and causes septic complications in diabetic foot syndrome / R. I. Sydorchuk, L. P. Sydorchuk, Khorshani Bilel [et al.] // Infection. - 2019. Vol. 47 (Suppl. 1). - S57-S58.

8. Diabetic Foot Australia guideline on footwear for people with diabetes / J. J. van Netten, P. A. Lazzarini, D. G. Armstrong [et al.] // J. Foot Ankle Res. - 2018. - Vol. 11. - P. 2.

9. Ozone application in multimodal treatment of pyoinflammatory complications in patients with diabetes mellitus / O. Y. Khomko, R. I. Sydorchuk, S. Y. Karateieva [et al.] // European Applied Sciences. - 2014. - Vol. 1. - P. 41-42.

10. Society for Vascular Surgery limb stage and patient risk correlate with outcomes in an amputation prevention program / M. W. Causey, A. Ahmed, B.Wu [et al.] // J. Vasc. Surg. - 2016. - Vol. 63. - P. 1563-1573.

11. Votruba P. Tracing the formalization steps of textual guidelines, in K. Kaiser, S. Miksch, S. Tu, eds. - Computer-based Support for Clinical Guidelines and Protocols. Proceedings of the Symposium on Computerized Guidelines and Protocols (CGP 2004). - Vol. 101 Studies in Health Technology and Informatics. IOS Press. - 2004. - P. 172-176.

\section{REFERENCES}

1. Schaper, N.C., van Netten, J., \& Apelqvist, J. On behalf of the International Working Group on the Diabetic Foot (IWGDF). IWGDF Guidelines on the Prevention and Management of Diabetic Foot Disease. Retrieved from: https://iwgdfguidelines. org/wp-content/uploads/2019/05/01-IWGDF-practicalguidelines-2019.pdf.

2. Nelson, A., Wright-Hughes, A., \& Backhouse, M.R. (2018). CODIFI (Concordance in Diabetic Foot Ulcer Infection): a crosssectional study of wound swab versus tissue sampling in infected diabetic foot ulcers in England. BMJ Open., 8 (1), e019437.

3. Chen, S.Y., Giurini, J.M., \& Karchmer, A.W. (2017). Invasive systemic infection after hospital treatment for diabetic foot ulcer: Risk of occurrence and effect on survival. Clin. Infect. Dis., 64 (3), 326-334.

4. Sartelli, M., Abu-Zidan, F.M., \& Labricciosa, F.M. (2019). Physiological parameters for Prognosis in Abdominal Sepsis (PIPAS) Study: a WSES observational study. World J. Emerg. Surg., 14 (34). Retrieved from; https://doi.org/10.1186/s13017019-0253-2.

5. Khomko, O.Y., Sydorchuk, R.I., Volyanyuk, P.M., Karliychuk, O.A., Petryuk, B.V., Bilyk, I.I., \& Knut, R.P. (2017). Status of immunity cellular link in diabetic foot syndrome. Klinicheskaya khirurgiya - Clinical Surgery, 8, 48-49.

6. Pavlovich, K.V., \& Sydorchuk, R.I. (2015). Vykorystannia iniektsiinoho materialu dlia reheneratsii shkiry latserta ${ }^{\circledR}$ dlia likuvannia trofichnykh vyrazok u khvorykh pry syndromi

diabetychnoi stopy [The use of injectable material lacerta ${ }^{\circledR}$ for the regeneration of skin in the treatment of trophic ulcers in patients with diabetic foot syndrome]. Klin. Khirurhiia-Clinical Surgery, 7, 44-46 [in Ukrainian].

7. Sydorchuk, R.I., Sydorchuk, L.P., Khorshani Bilel, Hrushko, O.I., Plehutsa, O.M., Sydorchuk, I., Plehutsa, I.M., Vakarchuk, A.V., Sydorchuk, A.R., Ilaschuk, I.I., \& Plehutsa, N. (2019). Microbiota alleviates host resistance and causes septic complications in diabetic foot syndrome. Infection., 47 (Suppl. 1), S57-S58.

8. Netten van J.J., Lazzarini, P.A., \& Armstrong, D.G. (2018). Diabetic Foot Australia guideline on footwear for people with diabetes. J. Foot Ankle Res., 11, 2.

9. Khomko, O.Y., Sydorchuk, R.I., Karateieva, S.Y., Makarova, E.V., Bilyk, I.I., \& Khomko, B.O. (2014). Ozone application in multimodal treatment of pyoinflammatory complications in patients with diabetes mellitus. European Applied Sciences, 1, 41-42. 10. Causey, M.W., Ahmed, A., \& Wu, B. (2016). Society for Vascular Surgery limb stage and patient risk correlate with outcomes in an amputation prevention program. J. Vasc. Surg., 63, 1563-1573.

11. Votruba, P., Miksch, S., Kosara. R. (2004). Tracing the formalization steps of textual guidelines. Kaiser, K., Miksch, S., Tu, S. (Eds.). Computer-based Support for Clinical Guidelines and Protocols. Proceedings of the Symposium on Computerized Guidelines and Protocols, volume 101 Studies in Health Technology and Informatics. IOS Press.

Отримано 17.09.2020 
V. P. POLYOVYY, BILEL KHORSHANI, O. V. ROTAR, O. M. PLEHUTSA, P. M. VOLIANIUK, O. Y. KHOMKO, P. V. KYFYAK, I. M. PLEHUTSA, R. I. SYDORCHUK

Bukovinian State Medical University, Chernivtsi

\section{INDIVIDUALIZED SURGICAL TACTICS FOR DIABETIC FOOT SYNDROME}

The aim of the work: to develop an individualized algorithm for surgical treatment of patients with diabetic foot syndrome (DFS). Materials and Methods. The comprehensive clinical study covers 123 cases of surgical treatment of DFS (patients of various degrees according to the PEDIS classification, I-V stages according to F. Wagner, with mild, moderate, severe infection according to IDSA). The development of the algorithm of surgical activity in DFS was carried out according to the recommendations of the Institute for Algorithmic Medicine (Houston, USA), using software (HTML/XML/GMT) package Document Exploration and Linking Tool/ ddons (DELTA) developed by Vienna University of Technology, Institute of Software Technology and Interactive Systems, Information Angineering Group, Vienna, Austria.

Results and Discussion. Angiographic or technical success of endovascular interventions, which leads to a significant increase in the lumen of the vessel in the area of stenosis or occlusion, was obtained in $94.3 \%$ of cases. The technical success of balloon angioplasty was observed in almost all cases; the slightly worse angiographic results were obtained with interventions on several arteries of the shin - 55.0-94.1\% of successful angioplasties. In ischemic and mixed neuroischemic forms, most patients were able to compensate for critical ischemia by performing vascular interventions. The proposed algorithm of surgical interventions for DFS requires further study under conditions of greater randomization and expansion of the cohort of patients.

Key words: diabetic foot syndrome; treatment; surgery; algorithm.

В. П. ПОЛЕВОЙ, БИЛЕЛ КХОРШАНИ, А. В. РОТАРЬ, А. М. ПЛЕГУЦА, П. М. ВОЛЯНЮК, О. И. ХОМКО, П. В. КИФЯК, И. М. ПЛЕГУЦА, Р. И. СИДОРЧУК

ВГУЗ Украины “Буковинский государственный медицинский университет”, Черновцы

\section{ИНДИВИДУАЛИЗИРОВАННАЯ ХИРУРГИЧЕСКАЯ ТАКТИКА ПРИ СИНДРОМЕ ДИАБЕТИЧЕСКОЙ СТОПЫ}

Цель работы: разработать индивидуализированный метод хирургического лечения больных синдромом диабетической стопы (СДС).

Материалы и методы. Комплексное клиническое исследование охватывает 123 случая хирургического лечения СДС (больные различной степени по классификации PEDIS, I-V стадий за F. Wagner, с легкой, умеренной, тяжелой инфекцией с IDSA). Разработку алгоритма хирургической активности при СДС осуществляли согласно рекомендациям Institute for Algorithmic Medicine (Хьюстон, США) с использованием программного (HTML / XML / GMT) пакета Document Exploration and Linking Tool / Addons (DELTA) разработанного Vienna University of Technology, Institute of Software Technology and Interactive Systems, Information Engineering Group, Vienna, Austria.

Результаты исследований и их обсуждение. Ангиографический или технический успех эндоваскулярных вмешательств, что приводит к существенному увеличению просвета сосуда в зоне стеноза или окклюзии, был нами получен в 94,3 \% наблюдений. Технический успех баллонной ангиопластики наблюдался практически во всех случаях, несколько хуже ангиографические результаты получены при вмешательствах на нескольких артериях голени - 55,0-94,1 \% успешных ангиопластики. При ишемической и смешанной нейроишемической формах у большинства больных удавалось компенсировать критическую ишемию выполнением сосудистых вмешательств. Предложенный алгоритм хирургических вмешательств при СДС требует дальнейшего изучения в условиях большей рандомизации и расширения когорты пациентов.

Ключевые слова: синдром стопы диабетика; лечение; хирургия; алгоритм. 